Habib Mohammad Reazaul Karim', Karen E.A. Burns², Laura D. Ciobanu ${ }^{3}$, Mohamad El-Khatib ${ }^{4}$, Antonello Nicolini ${ }^{5}$, Nicola Vargas ${ }^{6}$, Thierry Hernández-Gilsoul', Szymon Skoczyński ${ }^{8}$, Vito Antonio Falcone ${ }^{9}$, Jean-Michel Arnal ${ }^{10}$, John Bach ${ }^{11}$, Luca Salvatore De Santo ${ }^{12}$, Alberto Lucchini ${ }^{13}$, Joerg Steier ${ }^{14}$, Andrea Purro ${ }^{15}$, Angelo Petroianni ${ }^{16}$, Catherine S. Sassoon ${ }^{17}$, Stefano Bambi ${ }^{18}$, Margarida Aguiar ${ }^{19}$, Ayman 0. Soubani ${ }^{20}$, Corinne Taniguchi ${ }^{21}$, Corrado Mollica ${ }^{22}$, David A. Berlin ${ }^{23}$, Edoardo Piervincenzi ${ }^{24}$, Fabrizio Rao ${ }^{25}$, Ferini-Strambi Luigi ${ }^{26}$, Rodolfo Ferrari ${ }^{27}$, Giancarlo Garuti ${ }^{28}$, Gerhard Laier-Groeneveld ${ }^{29}$, Giuseppe Fiorentino ${ }^{30}$, Kwok M. Ho ${ }^{31}$, Jaber Saud Alqahtani ${ }^{32}$, Manuel Luján ${ }^{33}$, Onnen Moerer ${ }^{34}$, Onofrio Resta ${ }^{35}$, Paola Pierucci ${ }^{36}$, Peter Papadakos ${ }^{37}$, Stephan Steiner ${ }^{38}$, Sven Stieglitz ${ }^{39}$, Yalim Dikmen ${ }^{40}$, Jun Duan ${ }^{41}$, Pradipta Bhakta ${ }^{42}$, Alejandro Ubeda Iglesias ${ }^{43}$, Nadia Corcione ${ }^{44}$, Vânia Caldeira ${ }^{45}$, Zuhal Karakurt ${ }^{46}$, Gabriele Valli ${ }^{47}$, Eumorfia Kondili ${ }^{48}$, Maria Pia Ruggieri ${ }^{49}$, Margarida Simões Raposo ${ }^{50}$, Fabrizio Bottino ${ }^{51}$, Rafael Soler-González ${ }^{52}$, Mohan Gurjar ${ }^{53}$, José Luis Sandoval-Gutierrez ${ }^{54}$, Behrouz Jafari ${ }^{55}$, Marta Arroyo-Cozar ${ }^{56}$, Ana Roca Noval ${ }^{57}$, Nadia Corcione ${ }^{58}$, Igor Barjaktarevic ${ }^{59}$, Irena Sarc ${ }^{60}$, Bushra Mina ${ }^{61}$, Zbigniew Szkulmowski ${ }^{62}$, Corinne Taniguchi ${ }^{63}$, Antonio M. Esquinas ${ }^{64}$

'Department of Anesthesiology and Critical Care, All India Institute of Medical Sciences, Raipur, Great Eastern Road, Tatibandh, Raipur, India

${ }^{2}$ Critical Care Medicine, Li Ka Shing Knowledge Insitute, St. Michael's Hospital, Ontario Canada

${ }^{3}$ University of Medicine and Pharmacy "Grigore T Popa" lasi.; Clinical Hospital of Rehabilitation lasi, Romania

${ }^{4}$ Department of Anesthesiology, American University of Beirut-Medical Center, School of Medicine, Beirut, Lebanon

${ }^{5}$ Respiratory Diseases Unit. Hospital of Sestri Levante, Italy

${ }^{6}$ Geriatric and Intensive Geriatric Cares, "San Giuseppe Moscati" Hospital, Avellino, Italy

'Department, Instituto Nacional de Ciencias Médicas y Nutrición Salvador Zubirán; Critical Care, Instituto Nacional de Enfermedades Respiratorias Ismael Cosio Villegas. México

${ }^{8}$ Department of Pneumonology, School of Medicine in Katowice, Medical University of Silesia, Katowice, Poland

${ }^{9}$ Department of Basic Medical Sciences, Neurosciences and Sense Organs - Section of Respiratory Disease, University of Bari Aldo

Moro, Bari, Italy

${ }^{10}$ Intensive Care Department, Sainte Musse Hospital, Toulon, France

${ }^{11}$ Rutgers University New Jersey Medical School, USA

${ }^{12}$ Università della Campania Luigi Vanvitelli, Napoli and Cardiac Surgery Unit, AORN dei Colli, Naples, Italy

${ }^{13}$ General Intensive Care Unit — San Gerardo Hospital, Milano-Bicocca University, Milan, Italy

${ }^{14}$ King's College London, Faculty of Life Sciences and Medicine, London, UK

${ }^{15} \mathrm{Head}$ of Intensive Care Unit, Humanitas Gradenigo Hospital, Turin, Italy

${ }^{16}$ Respiratory Diseases Unit, Department of Cardiovascular and Respiratory Diseases, Policlinico Umberto I,

Sapienza University of Rome, Rome, Italy

${ }^{17}$ Division of Pulmonary and Critical Care Medicine University of California, Irvine, CA,; VA Long Beach Healthcare System,

Long Beach, CA, USA

${ }^{18}$ Medical \& Surgical Intensive Care Unit, Careggi University Hospital, Florence, Italy

${ }^{19}$ Pulmonologist, Pulmonary service, Hospital Beatriz Ângelo, Loures, Portugal

${ }^{20}$ Division of Pulmonary, Critical Care and Sleep Medicine, Wayne State University School of Medicine, USA

${ }^{21}$ Intenvise Care and Pneumology, Brazil

${ }^{22}$ High Dependency Respiratory Care Unit (STIRS) "S. Camillo-Forlanini" Hospital, Rome, Italy

${ }^{23}$ Department of Medicine, Weill Cornell Medicine New York, USA

${ }^{24}$ Università Sapienza di Roma, Rome, Italy

${ }^{25}$ Respiratory Unit, Neuromuscular OmniCentre (NeMO), Neurorehabilitation, University of Milan, Niguarda Hospital, Milan, Italy

${ }^{26}$ Sleep Disorder Unit, San Raffaele Hospital, Milan, Italy

${ }^{27}$ Emergency Department, University Hospital Sant'Orsola — Malpighi, Bologna, Italy

${ }^{28}$ Respiratory Unit, Santa Maria Bianca Hospital, Mirandola (MO), ASL Modena, Modena, Italy

${ }^{29}$ Department of Respiratory Medicine, Evangelisches Klinikum Niederrhein, Oberhausen, Germany

${ }^{30}$ Respiratory Unit, AO Ospedali dei Colli Naples PO Monaldi, Italy

${ }^{31}$ Department of Intensive Care Medicine, Royal Perth Hospital; School of Population \& Global Health, University of Western Australia; and School of Veterinary \& Life Sciences, Murdoch University, Perth, Australia

${ }^{32}$ Department of Respiratory Care, Prince Sultan Military College of Health Sciences, Dhahran, Saudi Arabia

${ }^{33}$ Pneumology Service. Hospital of Sabadell, Universitat Autónoma de Barcelona, Sabadell, Spain

${ }^{34}$ Department of Anaesthesiology, Georg-August-University, University Medical Center Göttingen, Germany

${ }^{35}$ Cardiothoracic department, Respiratory and Sleep medicine Unit, Policlinic, Bari "Aldo Moro" University, Italy

${ }^{36}$ Cardio-thoracic department.Respiratory and sleep Unit, Policlinic, Bari University Medical School, Bari, Italy

Address for correspondence: Antonio M. Esquinas MD, PhD, FCCP, Intensive Care Unit, Hospital Morales Meseguer, Murcia, Spain, Director International School of Non Invasive Mechanical Ventilation, e-mail:antmesquinas@gmail.com

DOI: 10.5603/ARM.a2019.0006

Received: 12.12 .2018

Copyright (C) 2019 PTChP

ISSN 2451-4934 
${ }^{37}$ Department of Anesthesiology and Surgery. Director CCM, University of Rochester, Rochester NY, USA

${ }^{38}$ Departement of Cardiology, Pneumology and Intensive care, St. Vincenz Hospital Limburg, Limburg, Germany

${ }^{39}$ Petrus Hospital Wuppertal, Academic Teaching Hospital of the University of Duesseldorf, , Clinic for Pneumology,

Allergology, Sleep- and Intensive Care, Wuppertal, Germany

${ }^{40}$ Istanbul University-Cerrahpasa, Cerrahpasa School of Medicine, Department of Intensive Care, Fatih, Istanbul

${ }^{41}$ Department of Respiratory Medicine, First Affiliated Hospital of Chongqing Medical University, Chongqing, Republic of China

${ }^{42}$ Department of Anaesthesia and Intensive Care, University Hospital Limerick, Dooradoyle, Limerick, Ireland

${ }^{43}$ Intensive Care Unit, Hospital Punta de Europa, Algeciras, Cádiz, Spain

${ }^{44}$ Departement of Anesthesia, Critical Care and Emergency, Fondazione IRCCS Ca' Granda — Ospedale Maggiore Policlinico, Milano, Italy

${ }^{45}$ Pneumology Department, Hospital Santa Marta, Lisboa, Portugal

${ }^{46}$ Pulmonary and Critical Care Department, Pulmonology and Intensivist, Dean in Hospital, University of Health Sciences, Istanbul, Turkey

${ }^{47}$ Department of Emergency Medicine, San Giovanni Addolorata, Rome, Italy

${ }^{48}$ Intensive Care Medicine, Medical School, University of Crete Greece, ICU University Hospital of Heraklion, Crete, Greece

${ }^{49}$ UOC PS-Breve Osservazione DEAI II livello AO San Giovanni Addolorata — Roma, Italy

${ }^{50}$ Centro Hospitalar de Lisboa Ocidental Egas, Moniz Hospital, Lisboa, Portugal

${ }^{51}$ Emergency Department, ASL 8, Arezzo, Italy

${ }^{52}$ Neurology Department. University Hospital of Melilla, Spain

${ }^{53}$ Department of Critical Care Medicine, Sanjay Gandhi Post Graduate Institute of Medical Sciences (SGPGIMS), Lucknow, India

${ }^{54}$ Instituto Nacional de Enfermedades Respiratorias, Mexico, Mexico

${ }^{55}$ Section of Pulmonary and Critical Care Medicine, University of California, Irvine, VA Long Beach Healthcare System, USA

${ }^{56}$ Servicio de Neumología, Hospital Universitario Infanta Cristina, Madrid, Spain

${ }^{57}$ Servicio de Neumologia, Hospital Universitario La Princesa, Madrid, Spain

${ }^{58}$ Department of Anesthesia, Critical Care and Emergency, Fondazione IRCCS Ca' Granda, Ospedale Maggiore Policlinico, Milan, Italy

${ }^{59}$ Division of Pulmonary and Critical Care Medicine, David Geffen School of Medicine at University of California, Los Angeles, USA

${ }^{60}$ Noninvasive ventilation department, University clinic for pulmonary and allergic diseases, Golnik, Slovenia

${ }^{61}$ Department of Medicine, Pulmonary and Critical Care Medicine, Northwell Health, Lenox Hill Hospital, New York, NY USA

${ }^{62}$ Departament of Anesthesia and ICU. University Hospital No 1 in Bydgoszcz. Collegium Medicum in Bydgoszcz. University Nicolaus

Copernicus in Toruń. Bydgoszcz, Poland

${ }^{63} \mathrm{Hospital}$ Israelita Albert Einstein, São Paulo, Brasil

${ }^{64}$ Director International School of Non Invasive Mechanical Ventilation, Intensive Care Unit, Hospital Morales Meseguer, Murcia, Spain

\title{
Noninvasive ventilation: education and training. A narrative analysis and an international consensus document
}

The authors declare no financial disclosure

\begin{abstract}
Noninvasive ventilation (NIV) is an increasingly used method of respiratory support. The use of NIV is expanding over the time and if properly applied, it can save patients' lives and improve long-term prognosis. However, both knowledge and skills of its proper use as life support are paramount. This systematic review aimed to assess the importance of NIV education and training. Literature search was conducted (MEDLINE: 1990 to June, 2018) to identify randomized controlled studies and systematic reviews with the results analyzed by a team of experts across the world through e-mail based communications.

Clinical trials examining the impact of education and training in NIV as the primary objective was not found. A few studies with indirect evidence, a simulation-based training study, and narrative reviews were identified. Currently organized training in NIV is implemented only in a few developed countries. Due to a lack of high-grade experimental evidence, an international consensus on NIV education and training based on opinions from 64 experts across the twenty-one different countries of the world was formulated. Education and training have the potential to increase knowledge and skills of the clinical staff who deliver medical care using NIV. There is a genuine need to develop structured, organized NIV education and training programs, especially for the developing countries.
\end{abstract}

Key words: noninvasive ventilation, training, education, programs, staff

Adv Respir Med. 2019; 87: 37-45 


\section{Contents}

Introduction

Importance and influence of staff training on outcomes with NIV .....

Evidence related to educational programs and the efficacy of NIV ......................................... 41

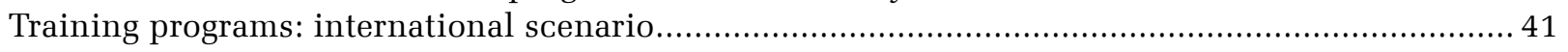

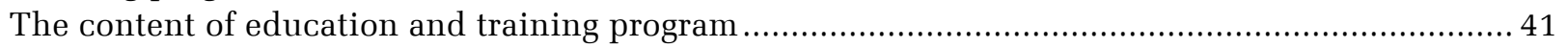

Problems to be addressed.

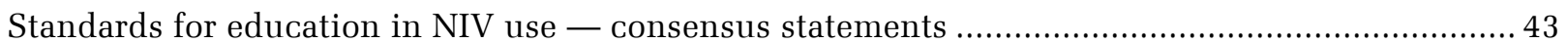

Conclusion

Abbreviations: ABG: arterial blood gas; AHRF: acute hypercapnic respiratory failure; ARF: acute respiratory failure; ARDS: acute respiratory distress syndrome; BTS: British Thoracic Society; CNVS: continuous noninvasive intermittent positive pressure ventilatory support; COPD: chronic obstructive pulmonary disease; CPAP: continuous positive airway pressure; ED: emergency department; ERS: European Respiratory Society; ICU: intensive care unit; NIV: non-invasive ventilation; $\mathrm{PCO}_{2}$ : partial pressure of carbon-di-oxide; RR: respiratory rate

\section{Introduction}

The education and training of medical personnel in noninvasive ventilation (NIV) is essential for reducing failures, complications and, ultimately, improving outcomes for patients with respiratory failure [1]. Proper NIV training would allow a successful use of NIV in stressful situations when patients are facing an acute life-threatening condition - such as Acute Respiratory Distress Syndrome (ARDS) or acute decompensated Chronic Obstructive Pulmonary Disease (COPD) - with a potential to delay or even avoid invasive ventilation. In this regard, adequate training of staff may improve cost-effectiveness of patient care, in addition to improving the clinical staff's job satisfaction. It is evident that in the modern hospital care setting, a proper training period for NIV should be part of the education of a multidisciplinary respiratory team and, indeed, all health care professionals who may need to handle patients with respiratory insufficiency. It is anticipated that a variety of clinical staff including pulmonology, emergency medicine, anesthesia, perioperative, and Intensive Care Unit (ICU) physicians, nurses and respiratory therapists are key players and stakeholders of the multidisciplinary NIV team. A comprehensive understanding of different causes of acute hypoxemic or hypercapnic respiratory failure, and also the utility, limitations, and technicalities of NIV is paramount, in addition to solid general knowledge and experience in intensive care medicine, including management of agitation and invasive hemodynamic monitoring.

Nurses and/or respiratory therapists are usually the frontline key personnel who deliver and monitor the NIV treatment in many healthcare institutions, and hence, their roles as part of the multidisciplinary respiratory team in the successful implementation of NIV cannot be understated. The quality of the interactions between nurses, physicians, respiratory therapists, patients, and their relatives has a substantial impact on the successful use of NIV by improving patients' compliance, detecting technical problems of the NIV equipment, and informing physicians whether the patients are responding well to the NIV treatment. The important roles of nurses in the successful implementation of NIV can be significantly compromised if they have not received the much-needed training and experience, especially in a low nurse to patient ratio setting.

Patients with respiratory insufficiency requiring NIV in the hospital environment are, by definition, seriously or critically ill and will require more frequent attention and care than other subjects in the general hospital wards. As such, specialized nurses who are knowledgeable and well-trained in NIV, with the skills of a respiratory therapist, may be particularly important if they can be designated to deal with ventilator settings, patient response, respiratory equipment, and monitoring exclusively in reducing patient-ventilator dyssynchrony and preventable NIV failure. If human resources are available, respiratory therapists and physiotherapists working closely with the nurses and other members of the multidisciplinary respiratory team can also be useful. In addition to assist sputum expectoration, physiotherapy can also provide advice and help patients to fully utilize the assistance of NIV in reducing their dyspnea and work of breathing [2]. Whenever more than a single person is involved, a cooperative and cohesive approach is paramount in maximizing the performance of 
the team; and this is only achievable through structured and organized education and training of all members of the NIV team [2].

Education can positively influence the medical intervention and the outcome. A structured ICU training program has been shown to be effective in improving the outcome even in the resource-limited area of Asia [3]. Similarly, resident training in communication in the ICU has shown to be associated with strongly positive family member outcomes and significant improvements in residents' perceived skills [4]. Simulation-based training has found its way in the medical education and instruction. Simulation has been defined as "a technique, not a technology, to replace or amplify real experiences with guided experience, often immersive in nature, that evokes or replicates substantial aspects of the real world in a fully interactive fashion" [4] Simulation-based medical teaching can therefore be defined as an educational activity which uses simulated components to replicate clinical practice [4]. Several systematic reviews [5-7] and at least two meta-analyses [8, 9] have investigated the effectiveness of simulation -based medical education in terms of knowledge and skills outcomes, and there is now a large body of good quality research evidence which demonstrates that simulation-based education is not only effective in terms of skills acquisition but also in translating the skills acquired in simulation-based training directly into practice to improve patient care and clinical outcomes. Simulation-based training has shown to improve four important items (i.e. physiology, indications, settings, and failure) in 762 participants in a high-fidelity online SBT program for NIV [10].

Currently, there are only few NIV simulator models which can be used to assess the user's competence in establishing ventilator settings and understanding and correctly responding to the effect of the ventilator on patient pathophysiology and tolerance. Evidence suggests simulation-based education is effective in terms of clinical skills acquisition and that these skills translate into improved patient care and clinical outcomes [7-9, 11]. In a study by Spadaro et al. [12], computer-based and mannequin-based approaches for training residents on MV were compared. This prospective randomized single-blind trial involved 50 residents. All participants attended the same didactic lecture on respiratory pathophysiology and were subsequently randomized into two groups: the mannequin group $(\mathrm{n}=25)$ and the computer screen-based simulator group $(\mathrm{n}=25)$. One week later, each group underwent a training assessment using five different scenarios of acute respiratory failure of various etiologies. Later, both groups underwent further testing of patient management, using in situ high-fidelity simulation of the patient with acute respiratory distress syndrome. In the final assessment, the scores of only the mannequin group significantly improved between the training and final session in terms of either global rating score [3.0 (2.5-4.0) vs. $2.0(2.0-3.0), p=0.005]$ or percentage of key score $(82 \%$ vs. $71 \%, \mathrm{p}=$ 0.001) [12].

\section{Importance and influence of staff training on the outcome with NIV}

It is a well-known fact that a proportion of patients undergoing NIV support will fail and eventually require intubation and invasive mechanical ventilation. Hence, delivering safe and effective NIV treatment depends on careful patient selection as well as the skills of physicians, nurses, and therapists. Personnel with an ability to use airway equipment to establish invasive ventilation should be readily available - if this was required urgently to avoid preventable mortality and morbidity in patients who develop rapid deterioration despite NIV. This issue is becoming more important as NIV is increasingly used to delay invasive ventilation - often planned as the last measure of respiratory support - in patients with severe respiratory failure.

Factors at the time of initiating NIV, or soon after, have been described to be able to predict the likelihood of its success, or failure, with a reasonable degree of certainty. The level of $\mathrm{pH}$ after a few hours of the NIV treatment is, first and foremost, of crucial importance [13]. A decrease in arterial $\mathrm{PCO}_{2}$ reflects the fact that the NIV therapy is effective in improving alveolar ventilation and most likely the work of breathing, and gives the rationale for continuation of NIV. Indeed, an improvement in respiratory rate (RR), heart rate, $\mathrm{PCO}_{2}$, consciousness and $\mathrm{pH}$ within one hour of NIV is highly predictive of successful use of NIV to avoid eventual invasive ventilation in hypercapnic respiratory failure [14] but is not indicative of late NIV failure likelihood. Careful bedside assessment of $R R$, the use of the respiratory accessory muscles, chest and abdomen movements along with an arterial blood gas (ABG) can indicate whether the patient is responding to NIV or is at risk of failed NIV requiring escalation of NIV support [15]. An unsuccessful initial NIV does not necessarily mean invasive ventilation is 
needed immediately, unless important strategies such as patient-ventilator dyssynchrony, air leak, patient compliance, and ventilator setting in terms of inspiratory time, rate and pressure have all been optimized. In addition, pharmacological therapy, including bronchodilators and diuretics, should also be considered to control any possible reversible elements.

A recent prospective observational study identified a number of factors associated with failed NIV treatment among a group of consecutive patients with acute hypercapnic respiratory failure (AHRF) requiring NIV in general medical wards. Although the number of patients included was small, the authors were able to identify suboptimal use of NIV due to a lack of training of the healthcare workers in all patients who failed NIV treatment $(p=0.007)$ [16]. Some of the errors detected were due to poor mask fitting with excessive air leaks, underskilled personnel who was incapable to deal with: ventilator alarms, control oxygen therapy using high flow, or even with simple ventilator settings control and adjustment. As a result, NIV was not used during some shifts because the present staff was not familiar with how to implement NIV strategies and operate NIV devices. The authors concluded that staff training was a key factor with a significant impact on NIV outcomes.

A striking difference has emerged as to NIV hard outcomes in published literature as compared to those reported in real-life surveys. NIV-related mortality for COPD exacerbation may be as low as $10 \%$ in experienced hands but as high as $30 \%$ in clinical practice $[17,18]$. These data reinforce the notion that team training (including all physicians, nurses and respiratory therapists if available) is crucial for NIV success and should be preferably focused on patient selection and close clinical surveillance. This may be frequently observed in real life but obviously will not be adequately shown in published data that NIV outcomes are frequently dependent on particular clinician skills rather than patients' severity.

Ideally, centers attending acute respiratory distress/failure patients should have a designated area for NIV, where appropriate equipment and well-trained staff are available. There is no doubt that suitable application of NIV by a trained and experienced team, together with careful patient selection, would optimize patient safety and outcomes. The providers should be able to identify when the limit of NIV has been reached or NIV failure is inevitable, using careful bedside assessment and ABG data within an hour or two of NIV use [19].
The proper use of NIV in hospitalized and home patients, through appropriate management and monitoring by the staff, allows reducing the costs and time of hospitalization and may prevent disease exacerbations [20-22].

Another study found that the time needed by a respiratory therapist to initiate NIV varied significantly with the levels of training [23]. Inadequate knowledge and skills have been shown as the reason for underutilization of NIV [24], and medical and nursing team members often feel ill-prepared to deliver NIV safely in accordance to guidelines [25]. This may explain why NIV remains underutilized despite the technology that has dramatically improved, and most NIV ventilators are user-friendly and easily available in many areas of different hospitals, including the emergency department (ED) and ward [24, 26].

A study demonstrated that optimized ventilation using flow and pressure waveforms analysis led to a more rapid normalization of $\mathrm{pH}$ at two hours (51 vs. $26 \%$ of patients) [27], as well as to a significant improvement of the patient's tolerance to ventilation at two hours, and to a higher decrease of $\mathrm{PCO}_{2}$. The authors concluded that NIV should be applied by a team with a great deal of experience in technological skills, such as the capability of analyzing the waveforms generated by the ventilator.

Overall, a certain skill mix of a multidisciplinary NIV team is needed to initiate and deliver safe and effective NIV treatment to patients with acute respiratory failure. Data from the literature indicates that, with the exception of the respiratory therapists, the level of knowledge and skills needed to deliver safe and effective NIV remains deficient among many healthcare professionals who are entrusted with managing patients with acute respiratory failure in different healthcare facilities [28-36].

The initiation of NIV has been reported to be time-consuming in the hands of inexperienced [23, 37]. The providers also need to be well versed in the constantly upgrading technologies and equipment. At present, the use of NIV is widespread, and NIV is routinely applied in ICU, intermediate care unit, respiratory wards, pulmonary rehabilitation premises, ED, palliative care unit and even in the hope for respiratory failures, neuromuscular diseases, etc. A different level of care and set-up requires a various degree of expertise and training for safe initiation and management of NIV. Therefore, multidisciplinary training in NIV is likely to bring considerable benefits to the provider as well as the patients. 


\section{Evidence related to educational programs and the efficacy of NIV}

A PubMed/MEDLINE advanced search for the duration of 1990 to the current date (June 25, 2018) with index word 'noninvasive ventilation', 'training', 'education', 'training/assessment', 'education/assessment' revealed no relevant clinical trial except few review articles. This may be caused by the fact that broad NIV utilization may be still considered as new but fast developing medical entity in which structured education and training were not broadly available. This indicates that the field is yet to be explored and the opinions of the experts confirm this. However, when a therapeutic intervention replaces the role of a vital organ or bodily function, as is the case in patients with little or no vital capacity who require continuous ventilatory support for survival, no controlled study is ethically possible [38].

One study examining the simulation-based training of staffs in NIV has been shown to be effective in skill development and is likely to play an important role in proper utilization [39].

\section{Training programs: international scenario}

Many centers and educational institutes give training in NIV within the professional education. This is particularly true for specialized ICU nurses, respiratory therapists, and pulmonologists and intensive care residents and even for the physicians entering the ICU. This is probably the norm and standard everywhere. However, specialized courses for in-depth knowledge and detailed application of NIV in practice are very much required. A training program in NIV is well prevalent in European as well as other developed countries. The European Respiratory Society (ERS) conducts both basic and advanced training in NIV [40, 41]. The project, Harmonized Education in Respiratory Medicine for European Specialists (HERMES) is a notable initiative of ERS in the field of respiratory medicine education $[42,43]$. The use of NIV in clinical practice in developing countries like India is not uncommon [43], but such organized education programs are lacking. Although the majority of the clinicians in India use NIV, marked variation in the patterns relating to actual deployment of NIV, site of initiation, protocols of initiation, and monitoring of patients have been reported [44]. Since few years in Poland, there have been NIV school courses organized by the Polish Respiratory Society which are directed to physicians and nurses. However, data suggesting organized teaching or education program from Asian and African countries are scarce.

By now, there are extensive and detailed reviews and recommendation 15 on NIV summarizing indications and practical applications such as ventilatory modes and settings, the role of interfaces, etc. These publications from the theoretical framework are intended to guide the use of NIV by pulmonologists and clinicians. However, these manuscripts give only a few suggestions on how to train doctors, nurses or physiotherapists. The BTS guidelines $[45,46]$ include some recommendations on training programs. It is advised that all staff involved in NIV service should receive training appropriate to their individual knowledge. This should include a combination of knowledge-based learning supported by practical experience in the workplace.

In many countries, the training is done mostly through workshop during different zonal and national conferences and is mainly limited to the doctors. This type of instruction has a limited impact on changing practice and does not support a unified training perspective for the NIV team within each healthcare facility [47]. The Tact Academy of Clinical Training is also running a two-day program for training in Mechanical Ventilation with a target audience of doctors and nurses [information from: http://www.tact-india. $\mathrm{com} / \mathrm{mechanical-ventilation-workshop-mv/].} \mathrm{Un-}$ like the European Respiratory Society, which runs training module for the NIV, the Indian Society of Critical Care Medicine (ISCCM) is yet to take that step even though ISCCM had published the guidelines for NIV in ARF more than a decade ago [48].

\section{Contents of the education and training program}

Training programs should build knowledge in a progressive manner to ensure understanding of various topics regarding NIV. This instruction should be compulsory to all health care professionals who care for patients requiring NIV, including not only physicians but also nurses, respiratory therapist, and physiotherapists. Training time needed for adequate education of health personnel involved in NIV is very variable in the studies, and there are currently no agreed standards. Some authors have suggested that an initial session of two hours three times a month may give an initial basis so as to start using NIV safely [1]. These sessions can be less frequent with increasing experience of the 


\section{Table 1. Minimum content of a training and education} program for healthcare staffs using NIV

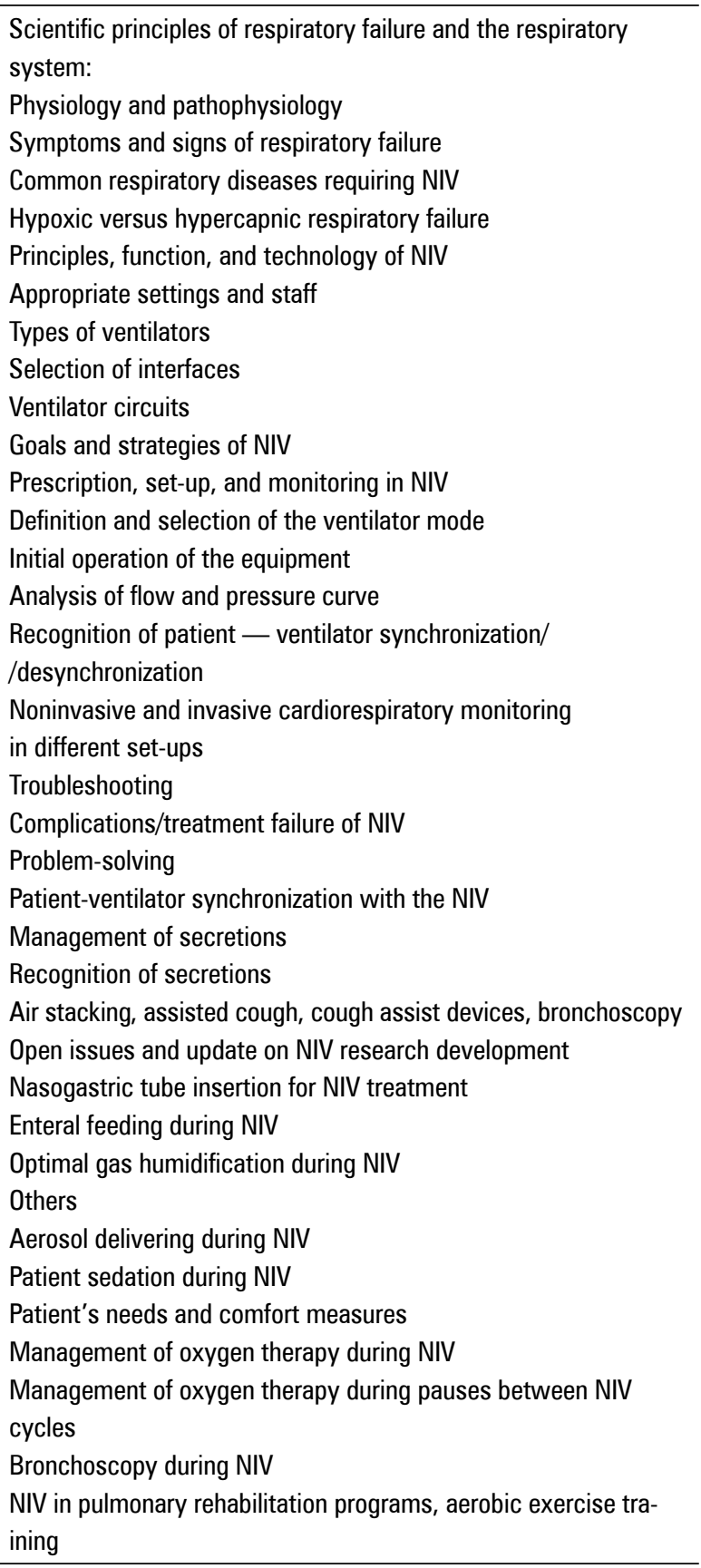

staff. Although the contents may vary slightly depending on the target audience (physicians, nurses, respiratory therapist, physiotherapists), generally speaking, they should include at least those listed in Table 1.

Optimal management of NIV requires that all members of the team are experienced and skillful. Physicians need to select patients who are likely to respond to NIV successfully and promptly identify those who are likely to fail or those showing signs of failed NIV. They must have the knowledge to select the most appropriate, best fitted mask to optimize patient comfort, reduce air leak, prevent skin lesion and also adjust the ventilator to efficiently alleviate respiratory distress. Nurses should be competent to monitor and have the ability to avoid, detect, troubleshoot both the patient and equipment problems. Quantifying the experience and skills of staff is challenging because individuals differ considerably and personnel changes can have important effects. Overall, outcomes appear to improve when units use NIV more frequently. Periodic education or training in-service and updates would help to maintain the skills of staff and also keep them stay abreast of new developments [49].

An ideal NIV education course should constitute $30 \%$ of lectures; $20 \%$ of dedicated interaction and question time for the participants followed by $50 \%$ of hands-on training. The total duration of the course and the rate of time to be spent on theory and practice sessions should be decided after taking into account the characteristics of the participants (roles, number, background and experience), the typologies of equipment, and the complexity of NIV modalities (e.g. high flow CPAP, Helmet/Mask PSV). The use of high fidelity simulation training could be useful for acquiring NIV skills. However, published literature about this method of learning of NIV know-how is still scant [28, 33, 39, 50-52].

The hands-on training sessions should offer the learners the opportunity to play the role of "the patient". The fitting of a mask, a helmet, and a direct experience of receiving PEEP and pressure support ventilation aids the trainees to understand the operation of NIV and its collateral effects on patients. It provides a unique opportunity for the participants to appreciate their future patients' NIV experience and ultimately would help them to manage real NIV situations at the patients' bedside. Like any other teaching programs, the education and training module should be audited and updated as per feedback and requirement followed by cycles of implementation, evaluation, modification, and re-implementation. Here we suggest the major components of the NIV training module and evaluation (Fig. 1).

Advanced educational NIV programs should also contain some skills in the interpretation of physiological waveforms (pressure-time/flow-time) assessing patient-ventilator synchrony. However, interpretation of such graphics is not easy, with huge discrepancies even between experts. In a recent study, 35 expert and 35 non-expert physicians examined NIV tracings, and the agreements 


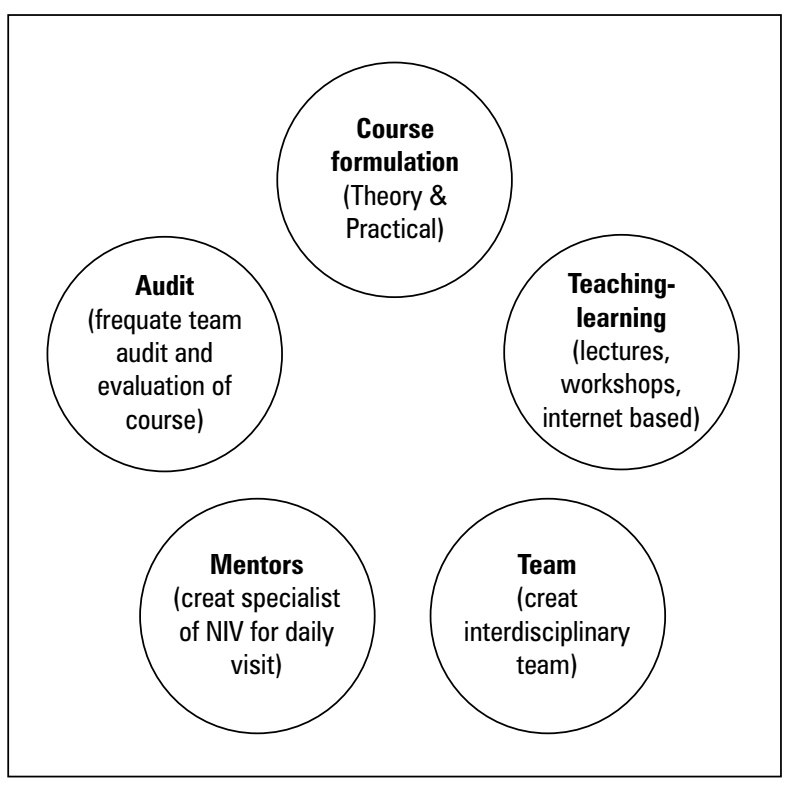

Figure 1. Noninvasive education and training cycle

were low in both groups (0.20/0.21) [53]. Patients with ARF are very fragile and timely action taken according to monitoring variables is one of the key elements for NIV success [54]. Therefore, patient monitoring in the different treatment settings needs to be considered as a dedicated skill.

NIV settings to be addressed:

Setting the mode - e.g., spontaneous/timed mode in the presence of central apnea or profound hypoventilation, with a failure to trigger inspiration support adequately by the patient.

Pressure setting - e.g., expiratory positive airway pressure to be titrated to abolish upper airway obstruction; inspiratory positive airway pressure is used to augment tidal volume and reverse nocturnal hypoventilation, evidenced by a reduction in respiratory effort and a rise in arterial or transcutaneous carbon dioxide.

Inspiratory duration (applicable only in spontaneous/timed mode) — increasing inspiratory time may rise tidal volume and mean airway pressure, improving gaseous exchange but at a cost of increasing air leak and poor patient tolerance. Inspiratory time should also be disease-specific, e.g. short inspiratory time in COPD. RR (applicable only in spontaneous/timed mode) — this is the minimum guaranteed rate and tend to increase minute ventilation, improve $\mathrm{CO}_{2}$ elimination, and unload respiratory muscle.

\section{Cycling criteria in the presence of a leak}

Method of attachment and method of removing the mask/interface - including quick chinstrap release, pressure areas due to the NIV interface.

\section{Complications}

Oxygen supplementation: Supplemental oxygen to be added if $\mathrm{SaO}_{2}$ persists $<90 \%$ during sleep, once settings are optimized [55]. The leak port circuit and leaking interface has shown to significantly reduce the supplemental oxygen concentration [56]. The oxygen enrichment should target $\mathrm{SaO}_{2}$ of $88-92 \%$ in AHRF in adults for a better outcome [57]. The interaction of flow, leakage, and interface with supplemental oxygen therapy and their management need to be addressed very well, and training and education is likely to improve the performance of the care providers.

\section{Standards for education in NIV use — consensus statements}

Numerous accrediting organizations are calling for competency-based medical education that would help define specific specialties and serve as a foundation for ongoing assessment throughout a practitioner's career. As there is relatively dearth of original research on this aspect, the 64 members of the present committee from twenty-one different countries across the world decided to have an international standard of education and training in NIV and agreed upon the following consensus:

The format and content of training and education of medical, nursing, physiotherapy personnel are essential in improving outcomes, reducing failures and avoid complications associated with the use of NIV.

Tertiary care centers and teaching institutes/ /universities caring for patients with acute respiratory failure should have a dedicated NIV training set-up, team and timing throughout the year for training and re-training. Using simulation-based teaching can improve training and education.

Secondary care hospitals, where NIV is used, should also adopt the training module as per their strength and ability and attend higher centers for updates in instruction and education from time to time.

Significant time is needed for adequate training and education of health personnel involved in the use of NIV; the time requirement is highly variable but should include repetitive sessions depending on the degree of expertise, and later on annual refresher courses/updates.

NIV providers should be trained to use all NIV equipment (e.g. interfaces and ventilators) that are available at their work location competently and should be further instructed after the introduction of newer technologies. 


\section{Conclusion}

Currently, there is little high-grade experimental evidence to support how best to train and educate NIV providers. Education and training in NIV have the potential to increase knowledge and skills of the staffs, and thereby improve short- and long-term outcomes. The development of structured, organized education and training programs catering for all members of the NIV team appears to be the need of the hour.

\section{Conflict of interest}

The authors declare no conflict of interest.

\section{References:}

1. Esquinas R, Martín UJ, Cordova FC, Criner GJ, González Dí. Organizaciónhospitalaria y formaciónclínicaenventilaciónmecánica no invasiva. In: Esquinas R. ed. Tratado de ventilaciónmecánica no invasiva. Prácticaclínica y metodología. Aula Medica, Madrid 2006: 1129-1134.

2. Simonds AK. Non-invasive respiratory support. A practical handbook. 2nd Ed. Arnold, London 2001: 230-45.

3. Haniffa R, Lubell Y, Cooper BS, et al. ICU Training in South Asia Group. Impact of a structured ICU training programme in resource-limited settings in Asia. PLoS One. 2017; 12(3): e0173483, doi: 10.1371/journal.pone.0173483, indexed in Pubmed: 28291809.

4. Sullivan AM, Rock LK, Gadmer NM, et al. The Impact of Resident Training on Communication with Families in the Intensive Care Unit. Resident and Family Outcomes. Ann Am Thorac Soc. 2016; 13(4): 512-521, doi: 10.1513/AnnalsATS. 201508-495OC, indexed in Pubmed: 26989925.

5. Gaba DM. The future vision of simulation in healthcare. Simul Healthc. 2007; 2(2): 126-135, doi: 10.1097/01. SIH.0000258411.38212.32, indexed in Pubmed: 19088617.

6. Ziv A, Ben-David S, Ziv M. Simulation based medical education: an opportunity to learn from errors. Med Teach. 2005; 27(3): 193-199, doi: 10.1080/01421590500126718, indexed in Pubmed: 16011941.

7. McGaghie WC, Issenberg SB, Petrusa ER, et al. Effect of practice on standardised learning outcomes in simulation-based medical education. Med Educ. 2006; 40(8): 792-797, doi: 10.1111/j. 1365-2929.2006.02528.x, indexed in Pubmed: 16869926.

8. Cook DA, Hatala R, Brydges R, et al. Technology-enhanced simulation for health professions education: a systematic review and meta-analysis. JAMA. 2011; 306(9): 978-988, doi: 10.1001/ jama.2011.1234, indexed in Pubmed: 21900138.

9. McGaghie WC, Issenberg SB, Cohen ER, et al. Does simulation -based medical education with deliberate practice yield better results than traditional clinical education? A meta-analytic comparative review of the evidence. Acad Med. 2011; 86(6): 706-711, doi: 10.1097/ACM.0b013e318217e119, indexed in Pubmed: 21512370.

10. Chatwin M, Hare A, Kurosinski P, et al. Evaluation of the educational outcomes of simulation-based training (SBT) for NIV. 2.2 Noninvasive Ventilatory Support. 2015, doi: 10.1183/13993003.congress-2015.oa4778.

11. Colt HG, Crawford SW, Galbraith O. Virtual reality bronchoscopy simulation: a revolution in procedural training. Chest. 2001; 120(4): 1333-1339, indexed in Pubmed: 11591579.

12. Spadaro S, Karbing DS, Fogagnolo A, et al. Simulation Training for Residents Focused on Mechanical Ventilation: A Randomized Trial Using Mannequin-Based Versus Computer-Based Simulation. Simul Healthc. 2017; 12(6): 349-355, doi: 10.1097/SIH.0000000000000249, indexed in Pubmed: 28825930 .
13. Confalonieri M, Garuti G, Cattaruzza MS, et al. Italian noninvasive positive pressure ventilation (NPPV) study group. A chart of failure risk for noninvasive ventilation in patients with COPD exacerbation. Eur Respir J. 2005; 25(2): 348-355, doi: 10.1183/09031936.05.00085304, indexed in Pubmed: 15684302.

14. Bhattacharyya D, Prasad B, Tampi PS, et al. Early predictors of success of non-invasive positive pressure ventilation in hypercapnic respiratory failure. Med J Armed Forces India. 2011; 67(4): 315-319, doi: 10.1016/S0377-1237(11)60075-0, indexed in Pubmed: 27365838.

15. Rochwerg B, Brochard L, Elliott MW, et al. Official ERS/ ATS clinical practice guidelines: noninvasive ventilation for acute respiratory failure. Eur Respir J. 2017; 50(2), doi: 10.1183/13993003.02426-2016, indexed in Pubmed: 28860265.

16. Lopez-Campos JL, Garcia Polo C, Leon Jimenez A, et al. Staff training influence on non-invasive ventilation outcome for acute hypercapnic respiratory failure. Monaldi Arch Chest Dis. 2006; 65(3): 145-151, doi: 10.4081/monaldi.2006.560, indexed in Pubmed: 17220104.

17. Plant PK, Owen JL, Elliott MW. Early use of non-invasive ventilation for acute exacerbations of chronic obstructive pulmonary disease on general respiratory wards: a multicentre randomised controlled trial. Lancet. 2000; 355(9219): 1931-1935, indexed in Pubmed: 10859037.

18. Roberts CM, Stone RA, Buckingham RJ, et al. National Chronic Obstructive Pulmonary Disease Resources and Outcomes Project implementation group. Acidosis, non-invasive ventilation and mortality in hospitalised COPD exacerbations. Thorax. 2011; 66(1): 43-48, doi: 10.1136/thx.2010.153114, indexed in Pubmed: 21075776.

19. Ozyilmaz E, Ugurlu AO, Nava S. Timing of noninvasive ventilation failure: causes, risk factors, and potential remedies. BMC Pulm Med. 2014; 14: 19, doi: 10.1186/1471-2466-14-19, indexed in Pubmed: 24520952.

20. Dretzke J, Blissett D, Dave C, et al. The cost-effectiveness of domiciliary non-invasive ventilation in patients with end-stage chronic obstructive pulmonary disease: a systematic review and economic evaluation. Health Technol Assess. 2015; 19(81): 1-246, doi: 10.3310/hta19810, indexed in Pubmed: 26470875.

21. Nicolini A, Stieglitz S, Bou-Khalil P, et al. Cost-utility of non-invasive mechanical ventilation: Analysis and implications in acute respiratory failure. A brief narrative review. Respir Investig. 2018; 56(3): 207-213, doi: 10.1016/j.resinv.2017.12.011, indexed in Pubmed: 29773291.

22. Patel SP, Pena ME, Babcock CI. Cost-effectiveness of noninvasive ventilation for chronic obstructive pulmonary disease -related respiratory failure in Indian hospitals without ICU facilities. Lung India. 2015; 32(6): 549-556, doi: 10.4103/09702113.168137, indexed in Pubmed: 26664158.

23. Kramer N, Meyer TJ, Meharg J, et al. Randomized, prospective trial of noninvasive positive pressure ventilation in acute respiratory failure. Am J Respir Crit Care Med. 1995; 151(6): 1799-1806, doi: 10.1164/ajrccm.151.6.7767523, indexed in Pubmed: 7767523.

24. Maheshwari V, Paioli D, Rothaar R, et al. Utilization of noninvasive ventilation in acute care hospitals: a regional survey. Chest. 2006; 129(5): 1226-1233, doi: 10.1378/chest.129.5.1226, indexed in Pubmed: 16685013.

25. Plumb JOM, Juszczyszyn M, Mabeza G. Non-Invasive Ventilation (NIV) a Study of Junior Doctor Competence !2010-3-17 ? 2010-05-15 !2010-06-30 ? The Open Medical Education Journal. 2010; 3(1): 11-17, doi: 10.2174/1876519x01003010011.

26. Vanpee D, Delaunois L, Lheureux P, et al. Survey of non-invasive ventilation for acute exacerbation of chronic obstructive pulmonary disease patients in emergency departments in Belgium. Eur J Emerg Med. 2002; 9(3): 217-224, indexed in Pubmed: 12394617.

27. Di Marco F, Centanni S, Bellone A, et al. Optimization of ventilator setting by flow and pressure waveforms analysis during noninvasive ventilation for acute exacerbations of COPD: a multicentric randomized controlled trial. Crit Care. 2011; 15(6): R283, doi: 10.1186/cc10567, indexed in Pubmed 22115190 . 
28. Hess DR. How to initiate a noninvasive ventilation program: bringing the evidence to the bedside. Respir Care. 2009; 54: 232-243.

29. Rose L, Gray S, Burns K, et al. Management of critically ill patients receiving noninvasive and invasive mechanical ventilation in the emergency department. Open Access Emerg Med. 2012; 4: 5-15, doi: 10.2147/OAEM.S25048, indexed in Pubmed: 27147858.

30. Cox CE, Carson SS, Ely EW, et al. Effectiveness of medical resident education in mechanical ventilation. Am J Respir Crit Care Med. 2003; 167(1): 32-38, doi: 10.1164/rccm. 200206-624OC, indexed in Pubmed: 12406827.

31. Nápolis LM, Jeronimo LM, Baldini DV, et al. Availability and use of noninvasive ventilation in the intensive care units of public, private and teaching hospitals in the greater metropolitan area of São Paulo, Brazil. J Bras Pneumol. 2006; 32(1): 29-34, indexed in Pubmed: 17273566.

32. Bierer GB, Soo Hoo GW. Noninvasive ventilation for acute respiratory failure: a national survey of Veterans Affairs hospitals. Respir Care. 2009; 54(10): 1313-1320, indexed in Pubmed: 19796410.

33. Davies JD, Gentile MA. What does it take to have a successful noninvasive ventilation program? Respir Care. 2009; 54(1): 53-61, indexed in Pubmed: 19111106.

34. Tallo FS, de Campos Vieira Abib S, de Andrade Negri AJ, et al. Evaluation of self-perception of mechanical ventilation knowledge among Brazilian final-year medical students, residents and emergency physicians. Clinics (Sao Paulo). 2017; 72(2): 65-70, doi: 10.6061/clinics/2017(02)01, indexed in Pubmed: 28273238.

35. Simonelli C, Paneroni M, Vitacca M. An implementation protocol for noninvasive ventilation prescription: the physiotherapist's role in an Italian hospital. Respir Care. 2013; 58(4): 662-668, doi: 10.4187/respcare.01891, indexed in Pubmed: 23051649.

36. Scala R, Windisch W, Köhnlein T, et al. European Respiratory Society Respiratory Intensive Care Assembly. Targeting European Respiratory Society Group activities: a survey of the Noninvasive Ventilatory Support Group. Eur Respir Rev. 2014; 23(132): 258-260, doi: 10.1183/09059180.00007213, indexed in Pubmed: 24881081.

37. Miller S, Latham M, Elliott MW. Where to perform NIV. Noninvasive Ventilation. 2008: 189-199, doi: 10.1183/1025448x.00041013.

38. Bach JR, Chiou M. Limitations of evidence-based medicine. Rev Port Pneumol (2006). 2016; 22(1): 4-5, doi: 10.1016/j. rppnen.2015.12.007, indexed in Pubmed: 26850653.

39. McQueen S, Dickinson M, Pimblett M. Human patient simulation can aid staff training in non-invasive ventilation. Nurs Times. 2010; 106(26): 20, indexed in Pubmed: 20698413.

40. Schönhofer B, Hart N, Scala R, et al. ERS noninvasive ventilation course: basic concepts. Breathe (Sheff). 2017; 13(2): 81-83, doi: 10.1183/20734735.002217, indexed in Pubmed: 28620427.

41. Advanced noninvasive ventilation course: the participants' view. Breathe (Sheff). 2016; 12(2): e20-e21, doi: 10.1183/20734735.004216, indexed in Pubmed: 27408643.

42. Mitchell S, Bloch KE, Butiene I, et al. "Education is the passport to the future": enabling today's medical teachers to prepare tomorrow's respiratory health practitioners. Eur Respir J. 2014; 44(3): 578-584, doi: 10.1183/09031936.00109314, indexed in Pubmed: 25176952.
43. Artigas A, Noël JL, Brochard L, et al. Defining a training framework for clinicians in respiratory critical care. Eur Respir J. 2014; 44(3): 572-577, doi: 10.1183/09031936.00104914, indexed in Pubmed: 25176951.

44. Chawla R, Sidhu US, Kumar V, et al. Noninvasive ventilation: a survey of practice patterns of its use in India. Indian J Crit Care Med. 2008; 12(4): 163-169, doi: 10.4103/09725229.45076, indexed in Pubmed: 19742261.

45. British Thoracic Society Standards of Care Committee. Non-invasive ventilation in acute respiratory failure. Thorax. 2002; 57(3): 192-211, indexed in Pubmed: 11867822.

46. Davies M, Allen M, Bentley A, et al. British Thoracic Society Quality Standards for acute non-invasive ventilation in adults. BMJ Open Respir Res. 2018; 5(1): e000283, doi: 10.1136/bmjresp-2018-000283, indexed in Pubmed: 29636979.

47. Burns KEA, Sinuff T, Adhikari NKJ, et al. Bilevel noninvasive positive pressure ventilation for acute respiratory failure: survey of Ontario practice. Crit Care Med. 2005; 33(7): 14771483, indexed in Pubmed: 16003051.

48. Chawla R, Khilnani GC, Suri JC, et al. Indian Society of Critical Care Medicine. Guidelines for noninvasive ventilation in acute respiratory failure. Indian J Crit Care Med . 2006; 10(117): 147.

49. Ozsancak Ugurlu A, Sidhom SS, Khodabandeh A, et al. Where should noninvasive ventilation be delivered? Respir Care. 2009; 54(1): 62-70, indexed in Pubmed: 19111107.

50. Hare A, Simonds A. Simulation-based education for non-invasive ventilation. Breathe. 2013; 9(5): 366-374, doi: 10.1183/20734735.006413.

51. Nayahangan LJ, Clementsen PF, Paltved C, et al. Identifying Technical Procedures in Pulmonary Medicine That Should Be Integrated in a Simulation-Based Curriculum: A National General Needs Assessment. Respiration. 2016; 91(6): 517-522, doi: 10.1159/000446926, indexed in Pubmed: 27287472.

52. Brill AK, Moghal M, Morrell MJ, et al. Randomized crossover trial of a pressure sensing visual feedback system to improve mask fitting in noninvasive ventilation. Respirology. 2017; 22(7): 1343-1349, doi: 10.1111/resp.13074, indexed in Pubmed: 28508568 .

53. Longhini F, Colombo D, Pisani L, et al. Efficacy of ventilator waveform observation for detection of patient-ventilator asynchrony during NIV: a multicentre study. ERJ Open Res. 2017; 3(4), doi: 10.1183/23120541.00075-2017, indexed in Pubmed: 29204431.

54. Ergan B, Nasiłowski J, Winck JC. How should we monitor patients with acute respiratory failure treated with noninvasive ventilation? Eur Respir Rev. 2018; 27(148), doi: 10.1183/16000617.0101-2017, indexed in Pubmed: 29653949.

55. Willson GN, Piper AJ, Norman M, et al. Nasal versus full face mask for noninvasive ventilation in chronic respiratory failure. Eur Respir J. 2004; 23(4): 605-609, indexed in Pubmed: 15083762.

56. Storre JH, Huttmann SE, Ekkernkamp E, et al. Oxygen supplementation in noninvasive home mechanical ventilation: the crucial roles of CO2 exhalation systems and leakages. Respir Care. 2014; 59(1): 113-120, doi: 10.4187/respcare.02596, indexed in Pubmed: 23801785.

57. Davidson AC, Banham S, Elliott M, et al. BTS Standards of Care Committee Member, British Thoracic Society/Intensive Care Society Acute Hypercapnic Respiratory Failure Guideline Development Group, On behalf of the British Thoracic Society Standards of Care Committee. BTS/ICS guideline for the ventilatory management of acute hypercapnic respiratory failure in adults. Thorax. 2016; 71 Suppl 2: ii1-i35, doi: 10.1136/ thoraxjnl-2015-208209, indexed in Pubmed: 26976648. 